\title{
Involvement of $M$ cells in the bacterial invasion of Peyer's patches: a common mechanism shared by Yersinia enterocolitica and other enteroinvasive bacteria
}

\author{
A Grützkau, C Hanski, H Hahn, E O Riecken
}

\begin{abstract}
Recent evidence indicates that ileal Peyer's patches represent the main infection route for Yersinia enterocolitica. In this study transmission and scanning electron microscopy have shown that only a small fraction of bacteria present in the lumen adhere to the follicleassociated murine epithelium with no discernible preference for either $M$ or absorptive cells. Yersiniae attached to $M$ cells are phagocytosed and transported from the lumen into the lamina propria. No invasion of columnar absorptive cells was observed. These data, in combination with recently published reports, indicate that the involvement of $M$ cells is a common step in bacterial invasion of Peyer's patches.
\end{abstract}

Pathogenic strains of Yersinia enterocolitica are known to cause ileitis, mesenteric lymphadenitis, and septicaemia in $\operatorname{man}^{1}$; and a similar reaction has been observed in the established model of murine yersiniosis. ${ }^{2}$

It has been shown recently in a mouse model that a pathogenic strain of $Y$ enterocolitica serotype 08 colonises ileal Peyer's patches about 1000 times more densely than surrounding epithelium of a comparable surface area. ${ }^{3}$ This selective colonisation seems to be due to a facilitated passage of bacteria through the epithelium of the Peyer's patches and the underlying basement membrane. ${ }^{3}$ Consequently, the pathogenic as well as the non-pathogenic strains of $Y$ enterocolitica can be detected in mesenteric lymph nodes ${ }^{45}$ as early as one hour after infection. ${ }^{6}$ How the bacteria penetrate the epithelium of Peyer's patches, however, has not been investigated in detail.

The adherence and invasion of cultured cells in vitro are coded by the chromosomal inv gene present in Yersinia pseudotuberculosis ${ }^{7}$ and $Y$ enterocolitica.$^{8}$ In vivo, however, the inv gene may be dispensable for virulence, since the bacteria missing this gene together with the gene coding for YOPl polypeptide are more virulent than the corresponding wild type strain. ${ }^{9}$ Recently, the chromosomal ail gene has been shown to correlate with the pathogenicity of Yersinia strains. ${ }^{10}$ The role of the inv and ail gene products and the mechanism of the Yersinia invasion in vivo have not yet been elucidated.

In the present work we used transmission and scanning electron microscopic techniques to investigate the initial events leading to the penetration of $Y$ enterocolitica into the ileal wall. In particular, it was of interest to determine whether the bacteria adhere to a specific cell in the lymphoid epithelium, which includes absorptive cells and $M$ cells. $M$ cells are specialised cells present in the follicle associated epithelium covering the lymphoid follicles of Peyer's patches of the small intestine. They are characterised by flat form, and fewer, shorter, and wider microvilli than absorptive cells, and by lack of lysosomes. These structural features of $M$ cells predestine them for the uptake and transport of antigens from the intestinal lumen into the underlying lymphoid tissue. ${ }^{11-15}$ This event could be an essential step during initiation of immune responses in the gastrointestinal tract.

\section{Materials and methods}

ANIMALS

Six to 8 week old female CD-1 mice weighing about $30 \mathrm{~g}$ were used. They were routinely checked for bacterial infection and were found free of common murine pathogens, including $Y$ enterocolitica. Mice were deprived of water for 24 hours before infection, but had free access to food. To prevent reinfection by coprophagy, the animals were placed in separate cages with grid bottoms.

BACTERIAL STRAINS AND GROWTH CONDITIONS The plasmidless strain NCTC 10598 and the isogenic plasmid bearing strain NCTC 10938 of $Y$ enterocolitica serotype $\mathrm{O} 8$ were obtained from the National Collection of Type Cultures, Central Public Health Laboratory (London, England). The bacteria were grown overnight at $24^{\circ} \mathrm{C}$ in brain heart infusion broth (BHI; Oxoid Ltd, London, England). For oral application, the plasmidless bacteria were diluted to $1 / 15$ in fresh $\mathrm{BHI}$ and incubated on a shaker at $28^{\circ} \mathrm{C}$ for six hours. The plasmidless and plasmid bearing bacteria used for ileal inoculation were also diluted to $1 / 15$ in fresh $\mathrm{BHI}$, but incubated on a shaker at $37^{\circ} \mathrm{C}$ for four hours.

\section{INFECTION OF MICE AND SCANNING ELECTRON} MICROSCOPY

To assure a high density of bacteria in the intestinal lumen, continuous infection with apathogenic bacteria in drinking water was chosen. Before application, the bacteria were spun down, washed twice with saline, and diluted with water to approximately $1 \times 10^{9}$ \\ 6 November 1989}




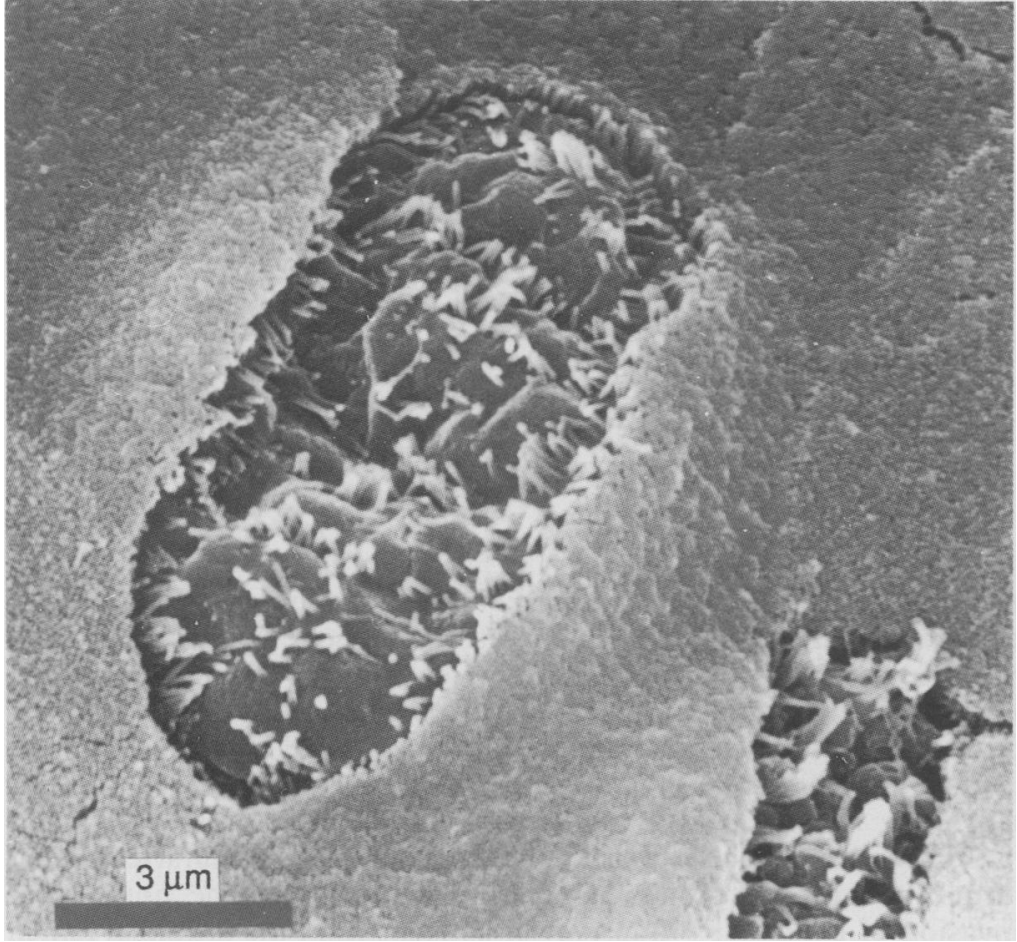

Figure 1: Resting $M$ cells in the Peyer's patch epithelium of an untreated mouse. Scanning electron micrograph. Bar, 3 um.

Figure 2: Distribution of bacteria on the dome epithelium of a murine ileal Peyer's patch during continuous infection $(36$ hours) with a non-pathogenic strain of Yersinia enterocolitica serotype 08 . One organism adheres to the protruding $M$ cell. Scanning electron micrograph. Bar, 3 $\mu \mathrm{m}$.

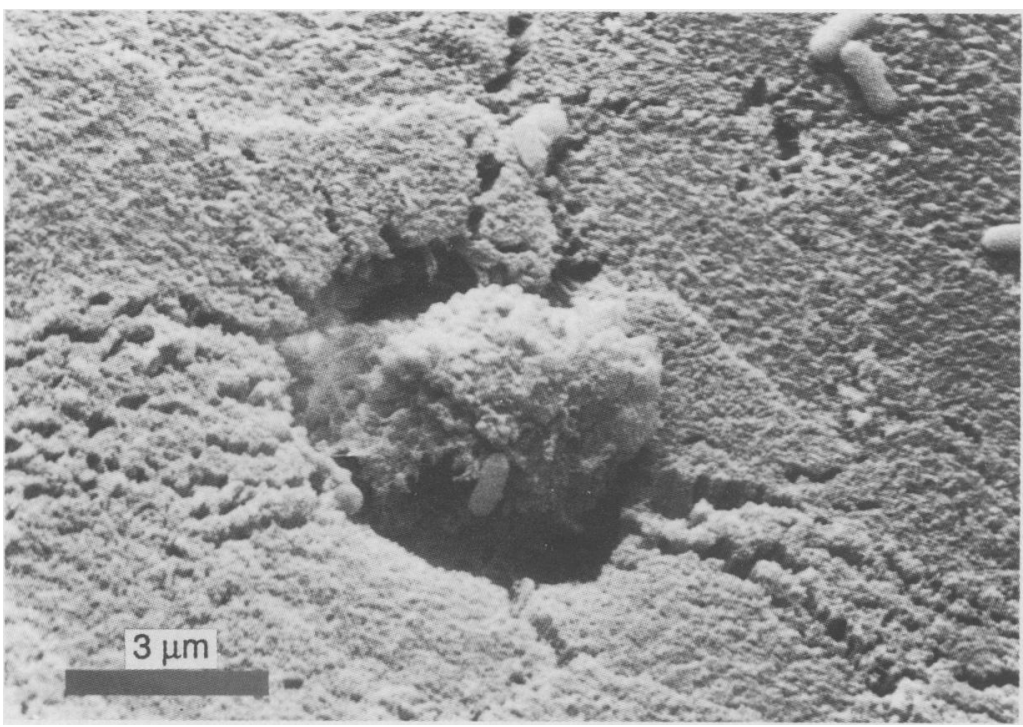

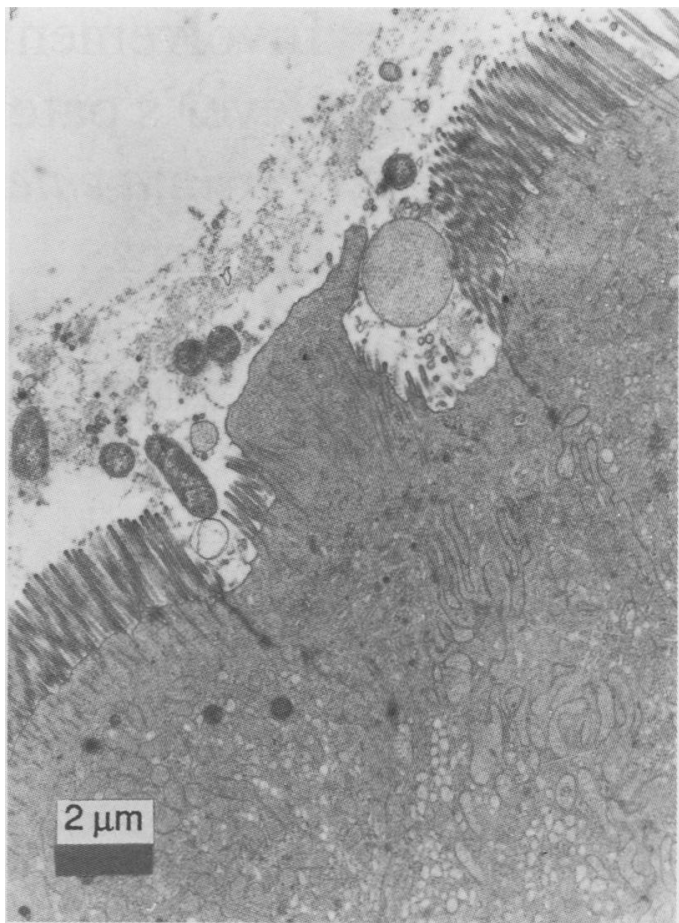

Figure 3: Phagocytosis of a luminal particle by the $M$ cell, 75 minutes after administration of apathogenic bacteria into the ileal loop. Yersinia enterocolitica in the close vicinity of $M$ cells neither bind nor invade the absorptive epithelium.

organism per ml. Six mice were then allowed to drink the bacterial suspension ad libitum for 36 hours. The total number of bacteria ingested by one mouse was approximately $1.0 \times 10^{10}$ per 12 hours. At specified times (12, 24, and 36 hours), mice were killed by $\mathrm{CO}_{2}$-treatment and the Peyer's patches of the small intestine were excised. The specimens were freed of luminal contents without washing and were then fixed in Karnovsky's fixans (3\% glutaraldehyde and 3\%

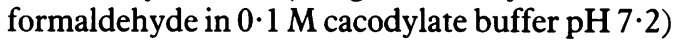
for 24 hours at $4^{\circ} \mathrm{C}$. Postfixation was carried out in $1 \% \mathrm{OsO}_{4}$ in $0 \cdot 1 \mathrm{M}$ cacodylate buffer $\mathrm{pH} 7 \cdot 2$ for one hour at $4^{\circ} \mathrm{C}$.

The tissue was then washed in $0 \cdot 1 \mathrm{M}$ cacodylate buffer, dehydrated in a graded series of ethanol solutions at room temperature, immersed in hexamethyldisilazane (Sigma, Deisenhofen, FRG) twice for 10 minutes each

Transmission electron micrograph. Bar, $2 \mu \mathrm{m}$.

time as described by Nation, ${ }^{16}$ air dried at room temperature, and mounted on aluminium disks. The samples were then coated with goldpalladium and investigated using a Philips EM 505 scanning electron microscope at $15 \mathrm{kV}$.

The Peyer's patches of non-infected mice, processed in parallel, showed no signs of infection or histological changes.

INFECTION OF MICE AND TRANSMISSION ELECTRON MICROSCOPY

Continuous infection represents a good approximation of a natural infection mode, yielding a high luminal colonisation. It does not, however, result in bacterial density high enough to enable investigation by transmission electron microscopy of the relatively rare event of bacterial penetration through the epithelium. For that purpose the ligated intestinal loop technique described by Wolf et al was used. ${ }^{12}$ By this method, a high luminal concentration of bacteria over Peyer's patches can be achieved and the earliest events of bacterial attachment and entry can be examined.

In brief, 10 mice were anaesthetised with urethane (Riedel de Haen, Seelze-Hannover, FRG; $140 \mathrm{mg} / 100 \mathrm{~g}$ body weight) given by intramuscular injection. The small intestine was made accessible by midventral laparotomy, and one $10 \mathrm{~cm}$ loop was prepared in the ileum using string ligatures. The ligated segment was inoculated either with a $600 \mu$ l suspension of approximately $2 \times 10^{9}$ viable pathogenic bacteria in $\mathrm{BHI}$ medium (the washed bacteria were diluted in fresh BHI medium) or with pure BHI (control loop). The abdomen was closed with clamps, and at specified times after inoculation $(30,60,75$, and 90 minutes) pairs of animals were killed. 


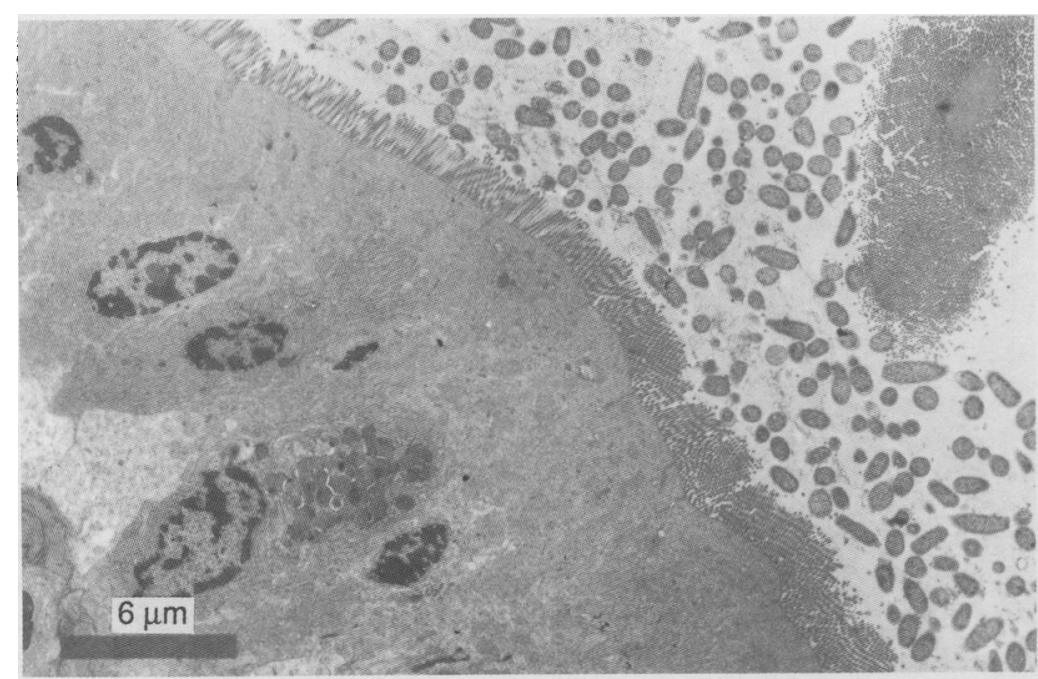

Figure 4: Lack of attachment of pathogenic Yersinia enterocolitica to the absorptive cells of Peyer's patch epithelium, 75 minutes after inoculation into the ileal loop. Transmission $\mu \mathrm{m}$. electron micrograph. Bar, 6

Control mice inoculated with pure medium were killed after 90 minutes. Another group of 10 mice was used in a parallel experiment for inoculation with plasmidless bacteria.

Specimen preparation, fixation, and dehydration were carried out as described for scanning electron microscopy. The dehydrated tissue was transferred to propylene oxide and embedded in Epon 812 resin (Serva, Heidelberg, FRG). Semithin sections $(0.5 \mu \mathrm{m})$ were mounted on glass slides and stained with toluidine blue for quick evaluation. Ultra-thin sections $(50 \mathrm{~nm})$ were picked up on copper grids and stained with uranyl acetate and lead citrate. Specimens were examined with a Philips 410 transmission electron microscope at $80 \mathrm{kV}$.

The specimens from control animals were processed in parallel to ensure that the animals had not been infected and that the Peyer's patches were intact.

Results

In the normal murine ileum of control mice,

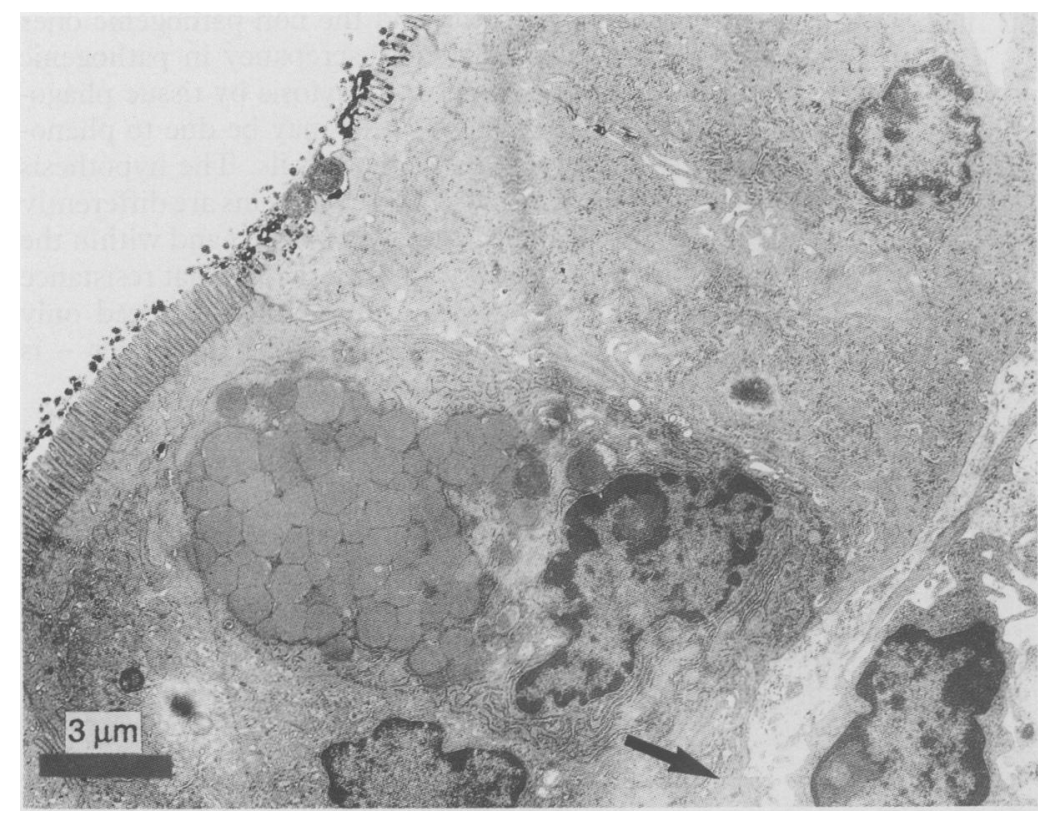

Figure 5: Initial interaction of two non-pathogenic Yersinia enterocolitica serotype O8 with an $M$ cell 60 minutes after intraluminal administration of the bacteria. The arrow indicates $a$ discontinuity of the basement membrane in the vicinity of the $M$ cell. Transmission electron micrograph. Bar, $3 \mu \mathrm{m}$.
M cells could be well recognised by scanning electron microscopy as characteristic depressions in the brush border of the follicle associated epithelium (Fig 1). In the infected mice, along with the typical retracted $M$ cells, another form of $M$ cells was observed which indicated their phagocytic capability. These $M$ cells were extending their pseudopodes into the lumen and engulfing luminal particles (Figs 2 and 3 ).

Numerous bacteria were found in the close vicinity of the brush border of the Peyer's patches as well as of the neighbouring villi; adhesion by pathogenic (Fig 4) and apathogenic (Fig 3) strains, however, was only seldom observed.

Bacteria adhering to the epithelium of Peyer's patches were distributed randomly, without any selective association with $M$ cells (Fig 2). This random distribution and rare adhesion to the epithelium was also observed after infection with the plasmid-bearing pathogenic strain. The adherent bacteria did not exhibit the capability of invading the absorptive epithelial cells (Fig 2). By contrast, binding to $M$ cells resulted in the uptake of the bacteria and their transport into the Peyer's patch dome (Figs 5, 6, and 7). The binding to $M$ cells did not result in formation of pedestals (Figs 5 and 7), which are observed during selective adherence of Escherichia coli strain RDEC-1 to $M$ cells. ${ }^{17}$

The recently published work on a pathogenic strain of $Y$ enterocolitica ${ }^{3}$ showed the proliferation of bacteria beneath the $M$ cells within 19 hours of infection. By contrast, no proliferation was observed in the case of apathogenic bacteria. Indeed, no plasmidless bacteria were found under the dome epithelium, indicating that the organisms transported through the $M$ cells were immediately eliminated or transported from the site of entry.

\section{Discussion}

The initial interaction of $Y$ enterocolitica with the ileal wall can be divided operationally into the adhesion-invasion phase, involving cells of the gut epithelium, and the proliferationelimination phase, resulting from the interaction with the lamina propria cells.

Several lines of evidence in vitro, ${ }^{7-818}$ and indirect evidence in vivo ${ }^{+619}$ indicate that the adhesion-invasion proceeds similarly in both plasmidless and plasmid bearing bacteria. The following step, however, is distinctly different: the plasmid-bearing bacteria proliferate, while the plasmidless organisms are eliminated.

Therefore, in the present work a plasmidless, non-pathogenic Yersinia strain of serotype $\mathrm{O8}$ was chosen for investigation of the initial binding and invasion of Peyer's patches. This strain does not cause epithelial lesions and permits the interaction of bacteria with the intact epithelium to be followed.

The present work shows that the investigated strain randomly adheres to the epithelial cells of the Peyer's patches and that the bacteria adhering to the $M$ cells are taken up and transported into the lamina propria. No invasion of absorptive epithelial cells was detected. The lack of selective binding to $M$ cells is concluded from the 
Figure 6: Binding and engulfment of nonpathogenic Yersinia enterocolitica serotype $O 8$ from ileal lumen into the Peyer's patch by an $M$ cell, 75 minutes after intraluminal administration of the bacteria. Transmission electron micrograph. Bar, $2 \mu m$.

Figure 7: Initial interaction and transport of apathogenic Yersiniae through $M$ cell, 60 minutes after inoculation into the ileal loop.

Transmission electron micrograph; Bar, 3 um.

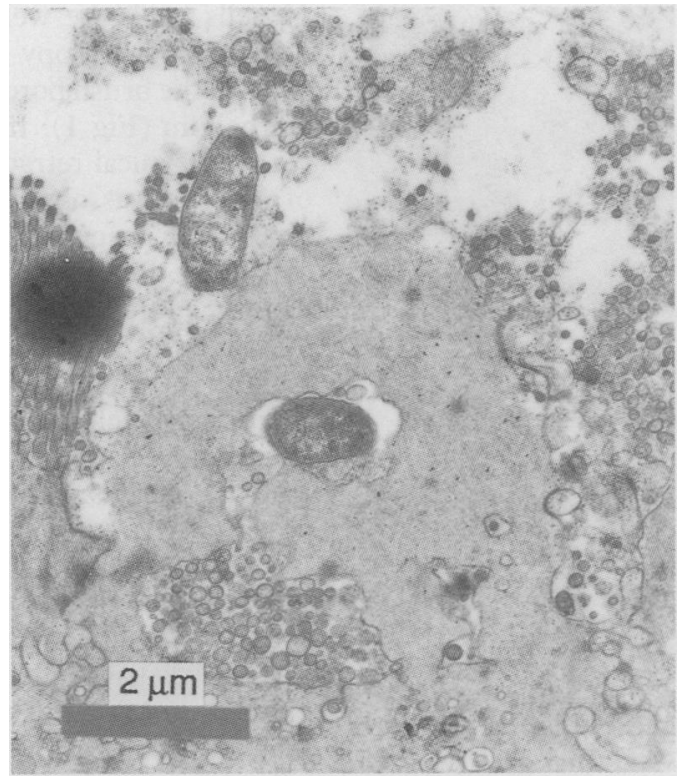

distribution of bacteria on the surface of the Peyer's patches as evaluated by scanning and transmission electron microscopy. Furthermore, pedestals described for specifically binding bacteria ${ }^{17}$ were not observed between $M$ cells and $Y$ enterocolitica (Figs 5 and 7).

After binding, bacteria were taken up by $M$ cells. This process closely resembled active phagocytosis (Figs 2 and 6). The phagocytic activity of $M$ cells is well documented by the work of Owen et al, who showed that horseradish peroxidase as well as non-invasive Vibrio cholerae are engulfed by these cells and transported into the lamina propria. ${ }^{11} 13$ The ability of $Y$ enterocolitica to invade epithelial cells in vitro has been documented by Miller and Falkow. ${ }^{810}$ There is, however, little information on the invasion of epithelium by $Y$ enterocolitica in vivo. Lian and Pai detected plasmidless as well as plasmidbearing bacteria, serotype $\mathrm{O} 3$, in the mesenteric lymph nodes within one hour of intragastric infection in rabbits. ${ }^{6}$ This fast and massive

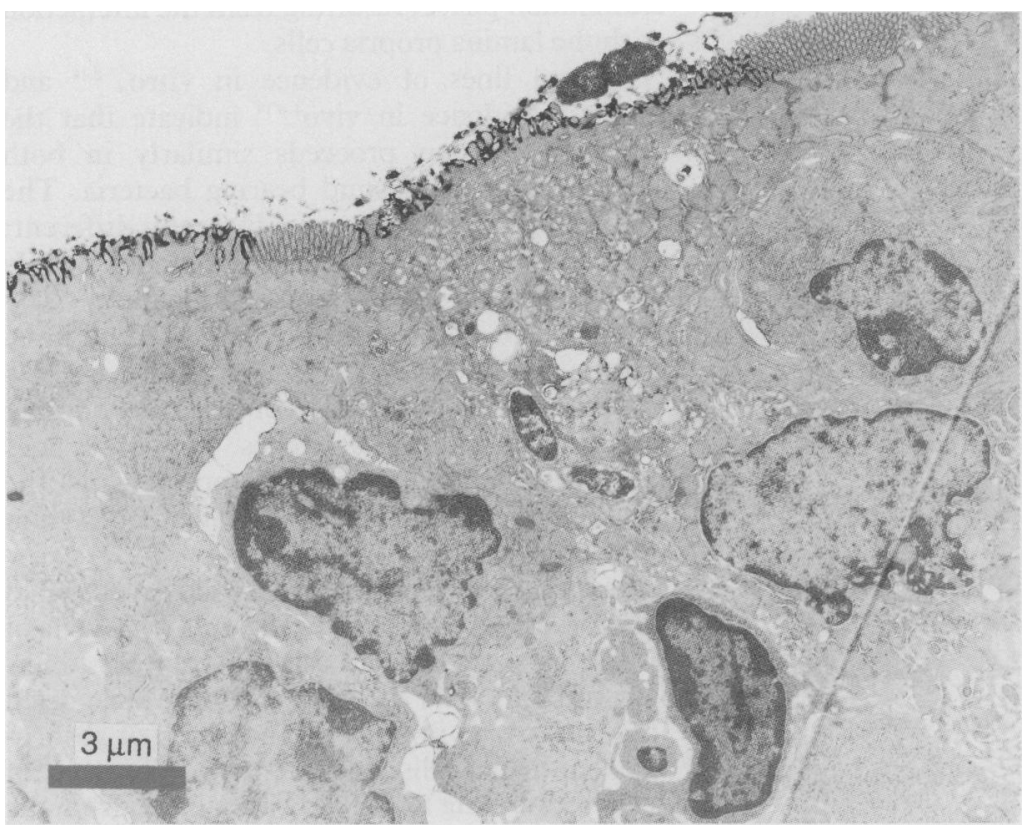

invasion of tissue, which was not observed in the present work, is probably due to the fact that $M$ cells represent up to $50 \%$ of the Peyer's patch epithelium in the rabbit, compared with $10 \%$ in the mouse.$^{20}$ No data, however, have been presented by Lian and Pai on cells responsible for the bacterial passage into the lamina propria.

In the present work, $M$ cells, but not absorptive cells, are shown to participate in the bacterial uptake. Electron microscopy does not permit determination of whether $Y$ enterocolitica enter the $M$ cells as a result of active host mediated uptake analogous to phagocytosis of horseradish peroxidase, " or by inducing the process known as parasite directed endocytosis. ${ }^{21}$ In view of the results obtained in vitro with $\mathrm{HEp}-2$ cells ${ }^{7}$ it is possible that the bacteria bind to the $M$ cell, which then reacts by engulfing and transporting them into the dome of the Peyer's patch. In either case the uptake is a positive virulence factor for the pathogenic strain, which resists elimination in the lamina propria by phagocytes, but a negative factor for the subsequently eliminated apathogenic strain. ${ }^{22}$ The additional determinant of the bacterial route of entry seems to be the structure of the basement membrane, which exhibits pores underneath Peyer's patch epithelium $^{3}$ (Fig 5) not found under the epithelium of the villous.

The involvement of $M$ cells in the binding or penetration, or both, of intestinal epithelium has been recently shown for Campylobacter jejuni, ${ }^{1+}$ Shigella flexneri, ${ }^{15}$ Salmonella typhimurium, ${ }^{23}$ and enteropathogenic $E$ coli. ${ }^{17}$ The present data on $Y$ enterocolitica lead to the conclusion that the involvement of the $M$ cells is a common step in the epithelial passage of the enteroinvasive bacteria.

In view of the indiscriminate interaction of pathogenic and non-pathogenic Yersiniae with the $M$ cells, the ability to survive and to proliferate in the tissue seems to be the decisive virulence factor.

In the lamina propria, pathogenic Yersinia strains proliferate and the non-pathogenic ones are eliminated. The discrepancy in pathogenic bacteria resisting phagocytosis by tissue phagocytes but not by $M$ cells may be due to phenotypic differences of these cells. The hypothesis that the plasmid-encoded proteins are differently expressed in the intestinal lumen and within the tissue of Peyer's patches - that is, that resistance to phagocytosis in vivo is fully acquired only after penetration of the epithelial barrier - is currently under investigation.

This work was supported by Deutsche Forschungsgemeinschaft, Grant No Ha 1520/2, and Maria Sonnenfeld Stiftung. The authors thank Prof Harald Stein for making available the scanning and transmission electron microscopy facility and Ms Illo Siebert for excellent technical assistance.

1 Bockemühl J. Die enteralen Yersiniosen: Pathogenese, klinischer Verlauf, Epidemiologie und Diagnose. Immun Infekt 1982; 10: 180-6.

2 Carter PB. Pathogenicity of Yersinia enterocolitica for mice. Infect Immun 1975; 9: 164-70.

3 Hanski C,Kutschka U, Schmoranzer HP, et al. Immunohistochemical and electron microscopic study of interaction of Yersinia enterocolitica serotype $\mathrm{O8}$ with intestinal mucos during experimental enteritis. Infect Immun 1989; 57: $673-8$ 
4 Robins-Browne RM, Tzipori S, Gonis G, Hayes J, Witners M, Prpic JK. The pathogenesis of Yersinia enterocolitica infections in gnotobiotic piglets. $\mathcal{F}$ Med Microbiol 1985; 19: 297-308.

5 Bakour R, Balligand G, Laroche Y, Cornelis G, Wauters G. A simple adult-mouse test for tissue invasiveness in Yersinia simple adult-mouse test for tissue invasiveness in Yersinia
enterocolica strains of low experimental virulence. $\mathcal{F}$ Med enterocolitica strains of low
Microbiol 1985; 19: 237-46.

6 Lian C-J, Hwang WS, Kelly JK, Pai CH. Invasiveness of Yersinia enterocolitica lacking the virulence plasmid: an in vivo-study. $\mathcal{F}$ Med Microbiol 1987; 24: 219-26.

7 Isberg RR, Voorhis D, Falkow S. Identification of Invasin: A protein that allows enteric bacteria to penetrate cultured mammalian cells. Cell 1987; 50: 769-78.

8 Miller VL, Falkow S. Evidence for two genetic loci in Yersinia enterocolitica that can promote invasion of epithelial cells. enterocolitica that can promote
Infect Immun 1988; 56: 1242-8.

9 Rosqvist R, Skurnik M, Wolf-Watz M. Increased virulence of Yersinia pseudotuberculosis by two independent mutations. Nature 1988; 57: 522-5.

10 Miller VL, Farmer III JJ, Hill WE, Falkow S. The ail locus is found uniquely in Yersinia enterocolitica serotypes commonly associated with disease. Infect Immun 1989; 57: 121-31.

11 Owen RL. Sequential uptake of horseradish peroxidase by lymphoid follicle epithelium of Peyer's patches in the normal unobstructed mouse intestine: An ultrastructural study. Gastroenterology 1977; 72: 440-51.

12 Wolf JL, Rubin DH, Finberg R, et al. Intestinal M cells: A pathway for entry of reovirus into the host. Science 1981; 212: 471-2.

13 Owen RL, Pierce NF, Apple RT, Cray WC Jr. M cel transport of Vibrio cholerae from the intestinal lumen into Peyer's patches: A mechanism for antigen sampling and for microbial transepithelial migration. $\mathcal{F}$ Infect Dis 1986; 153: 1108-18.

14 Walker RI, Schmauder-Chock EA, Parker JL. Selective association and transport of Campylobacter jejuni through $M$ cells of rabbit Peyer's patches. Can F Microbiol 1988; 34 1142-7.

15 Wassef JS, Keren DF, Mailloux JL. Role of $M$ cells in initial antigen uptake and in ulcer formation in the rabbit intestinal loop model of shigellosis. Infect Immun 1989; 57: 858-63.

16 Nation JL. A new method using hexamethylsilazane for preparation of soft insect tissues for scanning electron preparation of soft insect tissues for sc

17 Inman LR, Cantey JR. Specific adherence of Escherichia coli (stain RDEC-1) to membranous (M) cells of the Peyer's patch in Escherichia coli diarrhea in the rabbit. $\mathcal{F}$ Clin Invest 1983; 71: 1-8.

18 Portnoy DA, Moseley SL, Falkow S. Characterization of plasmids and plasmid-associated determinants of Yersinia enterocolitica pathogenesis. Infect Immun 1981; 31: 775-82.

19 Pai CH, DeStephano L. Serum resistance associated with virulence in Yersinia enterocolitica. Infect Immun 1982; 35 605-11.

20 Wolf JL, Bye WA. The membranous epithelial $(M)$ cell and the mucosal immune system. Ann Rev Med 1984; 35: the mucosa.

21 McGee ZA, Gorby GL, Wyrick PB, Hodinka R, Hoffman LH. Parasite-directed endocytosis. Rev Infect Dis 1988; 10 (suppl 2): S311-6.

22 Sneller MC, Strober W. M cells and host defense. $\mathcal{F}$ Infect Dis 1986; 154: 737-41.

23 Kohbata S, Yokoyama H, Yabuuchi E. Cytopathogenic effect of Salmonella typhi GIFU 10007 on M cells of murine ilea Peyer's patches in ligated ileal loops: an ultrastructural study. Microb Immunol 1986; 30: 1225-37. 